\title{
Limitación del derecho a la defensa por el plazo establecido en el procedimiento directo
}

\section{Limitation of the right to defense for the period established in the direct procedure}

Leydy Soraya Ruiz-Ramón

leydy.ruiz@psg.ucacue.edu.ec

Universidad Católica de Cuenca, Cuenca

Ecuador

https://orcid.org/0000-0003-4358-896X

Cecilia Ivonne Narváez-Zurita

inarvaez@ucacue.edu.ec

Universidad Católica de Cuenca, Cuenca

Ecuador

https://orcid.org/0000-0002-7437-9880

Juan Carlos Erazo-Álvarez

jcerazo@ucacue.edu.ec

Universidad Católica de Cuenca, Cuenca

Ecuador

https://orcid.org/0000-0001-6480-2270

Camilo Emanuel Pinos-Jaén

cpinosj@ucacue.edu.ec

Universidad Católica de Cuenca, Cuenca

Ecuador

https://orcid.org/0000-0002-0934-8471

Recibido: 15 de abril de 2020

Revisado: 17 de mayo de 2020

Aprobado: 25 de mayo de 2020

Publicado: 14 de junio de 2020 


\title{
RESUMEN
}

El presente artículo se centra en el análisis del Derecho Constitucional, en relación al procedimiento directo previsto en el Código Orgánico Integral Penal, con el objeto de establecer si este procedimiento cuenta con un plazo razonable conforme a los preceptos constitucionales del derecho a la defensa y el debido proceso. Metodológicamente se abordó desde una perspectiva descriptiva no experimental, se generó una profunda revisión bibliográfica en temas de derechos, garantías, plazo razonable con características análogas al procedimiento directo; los cuales fueron recolectados por medio de sentencias, libros, revistas, legislaciones y tratados internacionales, y demás. Queda reflejada la existencia de la vulneración del derecho a la defensa que consta en el procedimiento directo, por establecer un plazo divergente a lo establecido en la normativa constitucional y la Convención Americana sobre Derechos Humanos.

Descriptores: Procedimiento legal; derecho a la justicia; administración de justicia; sentencia judicial. (Palabras tomadas del Tesauro UNESCO).

\begin{abstract}
This article focuses on the analysis of Constitutional Law, in relation to the direct procedure provided for in the Comprehensive Organic Criminal Code, in order to establish whether this procedure has a reasonable period of time in accordance with the constitutional precepts of the right to defense and due process. Methodologically it was approached from a non-experimental descriptive perspective, a deep bibliographic review was generated on issues of rights, guarantees, reasonable time with characteristics analogous to the direct procedure; which were collected through judgments, books, magazines, legislation and international treaties, and others. The existence of the violation of the right to defense that is recorded in the direct proceeding is reflected, as it establishes a deadline that differs from that established in the constitutional regulations and the American Convention on Human Rights.
\end{abstract}

Descriptors: Legal procedure; right to justice; administration of justice; legal decisions. (Words taken from the UNESCO Thesaurus).

\section{INTRODUCCIÓN}

La vigencia de la Constitución de la República del Ecuador del año 2008 (CRE), trajo consigo una serie de cambios constitucionales y reformas para el sistema penal. Así, en 
el año 2014, entró en vigencia el Código Orgánico Integral Penal (COIP), innovando de un régimen penal inquisitivo a un acusatorio, lo cual significó adelantos en materia penal con obediencia a los preceptos constitucionales. En mayo del año 2019, la Asamblea Nacional reformó de manera parcial uno de los procedimientos especiales del COIP, el llamado procedimiento directo, donde se regla como plazo para la audiencia de juzgamiento 20 días, una vez que haya sido calificada la flagrancia.

Al respecto, la Constitución en forma expresa establece: "en todo proceso en el que se determinen derechos y obligaciones de cualquier orden, se asegurará el derecho al debido proceso (...) Contar con el tiempo y con los medios adecuados para la preparación de su defensa. (...)" (Asamblea Nacional, 2008, art. 76, numeral 7, letra b).

Así creado, este mecanismo de protección se convierte en parte esencial para el amparo de los derechos, en un ámbito específico de aplicable en el tiempo para preparar la defensa, sobre todo en el procedimiento directo, sustanciación que inicia con la audiencia de calificación de flagrancia, donde se trata como punto principal el llamamiento a juicio, en el plazo máximo de veinte días.

Este procedimiento especial tuvo sus primeros análisis y discusiones en el Ecuador hace cinco años, a pesar de existir adelantos relevantes con la reforma del año 2019, sigue siendo un tema muy debatido, con marcadas divergencias derivadas de la pugna existente entre el corto plazo que tiene el procedimiento directo para el juzgamiento y el plazo razonable con el que cuentan las partes para elaborar argumentos eficaces de defensa, de acuerdo con la teoría del caso, por lo que se contrapone con el sistema constitucional ecuatoriano, el desarrollo doctrinario en esta área; y, con el Sistema Interamericano de Derechos Humanos (SIDH).

En este estudio se analiza sobre el plazo razonable como parte de la garantía básica del debido proceso en el Derecho Constitucional, hasta llegar a mencionar el problema de la investigación y su solución, a través de revisión bibliográfica, legislación comparada de países como: Bolivia, Argentina, y Uruguay, análisis de sentencias; y, tratados internacionales, para describir qué está sucediendo con el plazo razonable en el 
procedimiento directo, pretendiendo una armonización entre plazo razonable y la garantía constitucional del debido proceso como parte del derecho a la defensa.

En virtud de lo antes indicado, el problema de la presente investigación consiste en identificar ¿cómo afecta al derecho a la defensa la inexistencia de un plazo razonable en el procedimiento directo?. Desde este aspecto, la presente investigación tiene como objetivo plantear la reforma del artículo 640, numeral 4 del COIP, referente al procedimiento directo como garantía para salvaguardar el derecho a la defensa.

\section{Referencial teórico}

\section{Derechos constitucionales de protección}

Para establecer la aproximación al concepto de debido proceso, (García, 2006) lo refiere como el desarrollo progresivo de todos los derechos fundamentales de carácter procesal o instrumental, que satisface las necesidades o intereses del ser humano; por lo que, se lo considera como un desenvolvimiento gradual de los derechos positivados del hombre, su importancia radica en asegurar su eficacia y la plena permanencia. En la misma línea, (García, 2010) indica que al respetar las normas jurídicas establecidas por el órgano competente, se garantiza un resultado jurídico que no se contraponga con ley. En este sentido, previo a ejecutar una causa judicial, es facultad del legislador establecer los lineamientos referentes a cómo se debe sustanciar un expediente a través de las leyes y reglamentos, sobre la base de la seguridad jurídica y la Constitución. Por su parte, (Santos, 2009) lo define como una garantía de carácter constitucional que debe ser aplicada en todo tipo de procesos para conseguir una justicia equitativa, con la finalidad de que las partes cuenten con las mismas oportunidades ante el juez .

A partir de los supuestos anteriores, este derecho es trascendental para garantizar la práctica las disposiciones constitucionales dentro de una causa judicial, al otorgar a las partes las mismas oportunidades ante la autoridad competente en el momento oportuno; el desarrollo de un juicio debe ser neutral y equitativo, esto se convierte en certeza 
cuando el avance del litigio se ha cimentado en el respeto a la Constitución y las normas jurídicas ya establecidas.

Bajo este contexto, el debido proceso al ser un derecho constitucional y tener como finalidad la protección de los intervinientes por medio de normas previas, hace que el derecho a la defensa se vincule a todos los procesos, por tanto, (Cruz-Barney, 2016) lo reseña como un derecho ilimitado; esto por cuanto se efectiviza en cualquier etapa del procedimiento. En este sentido, el Estado tiene la tarea de velar por el respeto de los derechos, por ser estos la columna vertebral de la Constitución, lo que genera una relación directa con el ciudadano (Baculima, Narváez, Trelles, \& Erazo , 2019), por lo que se observa que las personas son asistidas en la protección de sus intereses por medio de la ley, la Constitución o los tratados internacionales.

Al respecto, la CRE en su texto señala: "en todo proceso en el que se determinen derechos y obligaciones de cualquier orden, se asegurará el derecho al debido proceso" (...) (Asamblea Nacional Constituyente del Ecuador, 2008, art. 76). En consecuencia, las normas infra constitucionales, $y$, por consiguiente, los procesos jurisdiccionales contendrán este derecho por ser parte esencial en el desarrollo de una causa, sin importar el ámbito en el que se aplique. Es así que, la Carta Magna prevé de forma textual: “(...) 7. El derecho de las personas a la defensa incluirá las siguientes garantías: b) Contar con el tiempo y con los medios adecuados para la preparación de su defensa" (Asamblea Nacional Constituyente del Ecuador, 2008, art. 76). Esto garantiza que en todo proceso se cuente con el tiempo necesario para que las partes realicen sus diligencias y presenten sus pruebas.

Por otro lado, en razón del artículo 417 de la Constitución, el Ecuador ratifica los tratados internacionales (Asamblea Nacional Constituyente del Ecuador, 2008), como en efecto lo hace con el Pacto de San José, con fecha 21 de octubre del año 1977; a través de la Convención Americana sobre Derechos Humanos (CADH) que en el artículo 8 otorga el derecho a las personas a contar con el derecho al plazo razonable en el momento que 
requieran ser oídas (Organización de Estados Americanos, 1969). Por consiguiente, los tratados internacionales y la Constitución garantizan el debido proceso con el objeto de que los ciudadanos posean la seguridad de participar en un correcto desarrollo judicial, constituyéndose como eje fundamental en la sustentación de las causas, toda vez que permite un ejercicio real del derecho a la defensa.

En este sentido, la Convención antes citada hace referencia a las garantías jurisdiccionales, conforme el artículo 8 , numeral 2 , letra c, que consagra (...) "concesión al inculpado del tiempo y de los medios adecuados para la preparación de su defensa" (Organización de Estados Americanos, 1969, art. 8). De ahí que se garantiza los derechos de las personas involucradas en un proceso penal o de cualquier otro ámbito, a fin de ejercer su derecho a la defensa en un plazo prudente, donde las partes logren practicar las actividades procesales para la comprobación de la verdad y presenten sus pruebas según sea el caso.

Por su parte, el (Pacto Internacional de Derechos Civiles y Políticos, 1966) con la intención de garantizar este mismo derecho, manifiesta que las personas procesadas dispondrán del derecho a escoger quién patrocine su defensa y por medio de ésta, a ser oído en el momento y tiempo adecuados. Es importante recalcar que tanto la Declaración Universal de Derechos Humanos en el artículo 10 (Asamblea General de las Naciones Unidas, 1948), como la Declaración Americana de los Derechos Humanos y Deberes del Hombre, artículo 26, otorgan a las partes procesales el derecho a la defensa que se viabiliza frente al juez al ser escuchadas en el momento oportuno (IX Conferencia Internacional America, 1948).

En este orden de ideas, las disposiciones salvaguardan la garantía de un proceso justo al otorgar a las personas las herramientas necesarias para que se desarrolle un juicio equitativo, en igualdad de condiciones. Gozar del tiempo conveniente y contar con mecanismos oportunos para la defensa, permite desplegar los suficientes medios probatorios para defender la teoría a presentar en un litigio judicial. 
La Corte IDH hace efectivos estos derechos en la sentencia, Caso del Tribunal Constitucional vs. Perú, de fecha 31 de enero de 2001, donde concluye que las garantías mínimas señaladas en el artículo 8.2 de la Convención, no deben coartar las contiendas legales en forma estricta, puesto que si existen trámites en los que se resuelva sobre derechos y obligaciones deben primar las garantías enunciadas, sin importar la naturaleza donde se desenvuelva(Caso del Tribunal Constitucional vs. Perú, 2001).

Por lo que se observa, que a más de la Constitución, los tratados internacionales y la Corte IDH, con gran énfasis muestran que no se debe coartar el derecho a la defensa ni lo que éste conlleva en ningún tipo de procedimiento. En fin, se establece la relevancia de estos derechos, ya que permiten iniciar una contienda legal con normas encaminadas a la protección del ser humano.

En este punto, en el ámbito penal, el Art. 640 del Código Orgánico Integral Penal, numeral 4 , referente al procedimiento directo, contradice los preceptos del derecho a la defensa al disponer que las partes procesales cuenten con un plazo de 20 días para anunciar los medios probatorios, preparar una defensa técnica y ser juzgado, lo que impide el ejercicio de las garantías constitucionales que aseguran el respeto al debido proceso.

\section{Analogía del procedimiento directo con otras legislaciones sudamericanas}

La legislación penal ecuatoriana cuenta con dos tipos de procedimientos, el ordinario y los especiales, entre los cuales se encuentra el procedimiento directo. En este estudio se analiza hasta qué punto el plazo establecido en el procedimiento directo se contrapone con los derechos constitucionales. Al respecto, (Grunauer, 2016) efectúa una crítica al procedimiento directo, al señalar que con el fin de descongestionar los órganos judiciales, acumula las etapas del procedimiento en una audiencia única, sin embargo, el tiempo señalado para ingresar la carga probatoria resulta ínfimo. Pues bien, el Estado al intentar adaptarse a las nuevas necesidades de la sociedad en la esfera penal, implementa un procedimiento con un plazo que difiere con la Constitución, por limitar el plazo para la defensa. 
Hasta noviembre del año 2019, el COIP en el artículo 640, dispuso que el procedimiento directo debía sustanciarse de acuerdo con algunas reglas, parte de ellas indicaban que una vez calificada la flagrancia, el juez llamará a la audiencia de juzgamiento en diez días plazo; hasta tres días antes de la audiencia, las partes debían incorporar la prueba (Asamblea Nacional del Ecuador, 2014). Posterior a ello, la Asamblea Nacional por las atribuciones que le concede la Constitución, reformó dicho procedimiento mediante la Ley Orgánica Reformatoria al Código Orgánico Integral Penal, suplemento número 107, de fecha 24 de diciembre del año 2019 -que entrará en vigencia a partir de junio de 2020-, la cual modifica el plazo aumentándolo a veinte días para que se instale la audiencia de juzgamiento. De igual forma, en la audiencia de calificación de flagrancia las partes podrán solicitar la práctica de diligencias, y en casos excepcionales, se podrá incorporar prueba nueva que se considere fundamental para la defensa en dicha audiencia (Asamblea Nacional del Ecuador, 2019).

A pesar de la reforma, la norma penal restringe derechos constitucionales al implantar un plazo insuficiente. Si bien es cierto, el legislador tuvo la intención de modificar esta vulneración a los derechos constitucionales, al incrementar el plazo a veinte días y al permitir que el día de la audiencia de juicio se agregue prueba no anunciada, este tiempo limita el espíritu de la norma constitucional y de los tratados internacionales que disponen con claridad que todos los ciudadanos deben contar con la garantía básica del debido proceso, lo que asegura un plazo razonable al brindar la convicción de ser juzgado en un juicio justo.

En este caso, el plazo de veinte días no constituye un tiempo prudente para ser juzgado, más aún, cuando el COIP en su artículo 573, describe al plazo como la contabilización de todos los días y horas para el trámite de actos procesales (Asamblea Nacional del Ecuador, 2014), esto conlleva a que el imputado posea escasos diecisiete días, incluidos fines de semana y días feriados, para incorporar su prueba y preparar su defensa técnica. El hecho de que el procedimiento otorgue la facilidad de ingresar el día de la audiencia 
de juicio otros elementos probatorios, afianza la teoría que tanto la víctima, el procesado y la Fiscalía no cuentan con un plazo razonable para preparar sus argumentos.

En virtud de ello, el procedimiento directo limita a las partes a que puedan ejercer su derecho a la defensa, al no contar con el tiempo y los medios necesarios para dar cumplimiento a diligencias probatorias, siendo necesario extender el plazo para efectivizar el cumplimiento de los derechos estatuidos en la norma constitucional y los instrumentos internacionales. En síntesis, el Ecuador mantiene en el procedimiento directo un plazo muy reducido, por lo que es necesario que se arribe a una comparación de legislaciones con procedimientos análogos, con el fin de determinar el incumplimiento de los derechos prescritos en la Constitución en el COIP. Para lograrlo, se realiza una revisión de diferentes normativas sudamericanas, donde se observa que existen varios procedimientos similares al ecuatoriano, conforme se describe en la tabla uno:

\section{Tabla 1}

Procedimiento directo en diferentes normativas sudamericanas

\begin{tabular}{lcc} 
País & Artículo & Plazo \\
\hline Argentina & 17 & 60 días \\
Bolivia & 393 & 45 días \\
Uruguay & 128 & 30 días / en reforma a 45 \\
& & días \\
\hline
\end{tabular}

Fuente: Ley 13811, Ley 007, Ley 19293.

Como se observa, estos procedimientos aunque con diversas denominaciones, cumplen con la misma finalidad que el procedimiento directo, es decir, aplica en casos de flagrancias y gozan de celeridad; la diferencia relevante es que ninguna legislación sostiene un plazo máximo de veinte días para ser juzgado. En Uruguay se tramita en el plazo de treinta días, con proyección a cuarenta y cinco días según la reforma de Ley Urgente de febrero del año 2020; de manera similar, Bolivia cuenta con el plazo de 
cuarenta y cinco días; y, en Argentina el plazo es aún más extenso, con sesenta días. (Senado y Cámara de Diputados de la Provincai de Buenos Aires, 2008); (Ministerio de Justicia, 2010); y, (Senado y Cámara de Representantes de la República Oriental del Uruguay, 2015).

En consecuencia, se determina que mientras más amplio sea este plazo, mayor es la garantía y el respeto de los derechos constitucionales que rigen estos procedimientos, pues aseguran el pleno goce del derecho a la defensa y el debido proceso dentro de un plazo razonable. De la revisión de legislaciones internacionales se deduce la importancia para la problemática de estudio ya que coadyuva a la evolución del derecho penal ecuatoriano.

\section{La importancia del plazo razonable en el procedimiento directo}

Con relación a la problemática, se instruye que el factor tiempo ha sido vital a la hora de definir el desarrollo de un procedimiento, al flexibilizar los plazos en el momento de diseñar una norma que permita asegurar un debido proceso con énfasis en el derecho a la defensa; lo que evidencia la importancia de la actividad probatoria, siempre que su anunciación y su consecuente práctica esté exenta de cualquier tipo de condición limitadora que atente con el eficiente desenvolvimiento procesal (Rojas, Erazo, Pozo, \& Narváez, 2019). De la afirmación antecedente, se desprende que el acceso a la prueba no debe ser restringido por ningún concepto, pues representa un atentado directo al debido proceso.

Por consiguiente, el plazo razonable está intrínsecamente relacionado con la oportunidad de recolectar prueba eficaz que servirá dentro del juicio, la misma que tiene mayor incidencia en las causas penales, por estar en juego la libertad de las personas (Rivadeneyra, 2010). Ante ello, se desprende la vinculación directa que tiene el plazo razonable con el debido proceso, por lo que juega un papel clave dentro de los procedimientos penales, que al no brindar un tiempo necesario, puede incidir en un factor determinante que afecte la libertad del procesado. 
La Corte Interamericana de Derechos Humanos (Corte IDH) sostiene una línea jurisprudencial al afirmar que es importante examinar las circunstancias de cada proceso, conforme lo señalado en los casos (Tarazona Arrieta y otros vs. Perú, 2014), sentencia de fecha 15 octubre del año 2014; y, caso (Caso Argüello y otros vs. Argentina, 2014), sentencia de fecha 20 de noviembre del año 2014. En este sentido, para precisar la prudencia del plazo se tomaron en cuenta los siguientes parámetros:

a) Complejidad del asunto. - Está enmarcado entre la dificultad probatoria, la cantidad de sujetos intervinientes, el número de afectados.

b) Actividad procesal del interesado.- Importancia con la que sustentan las partes el desarrollo de los procedimientos, es decir, la serie de actos encaminados a probar su teoría del caso.

c) Conducta de las autoridades judiciales.- Actuación de los jueces sobre la base de sus atribuciones conforme a normas jurídicas pre establecidas que inciden en cada una de las etapas del proceso.

d) Afectación jurídica de la persona involucrada.- Influencia del tiempo trascurrido dentro de una contienda legal que devengue en el menoscabo de derechos positivados. Las conceptualizaciones anteriores definen los lineamientos a considerase en el plazo razonable, en base que cada contienda legal cuenta con diferentes elementos, como son el número de participantes, diligencias que conlleven al impulso de la defensa, la conducta del juez y el grado de vulneración del procesado. No obstante, la Corte IDH no precisa un plazo específico en número de días que la duración de los procesos, sino que propone algunos criterios a ser considerados por cada órgano judicial, con el fin de dilucidar el nivel de afectación del derecho a ser juzgado dentro de un plazo coherente. La Corte IDH, realiza una acertada interpretación de este derecho fundamental, al indicar que, para señalar la razonabilidad de un plazo dentro de una contienda judicial, se debe analizar la complejidad y la actividad procesal. En esta investigación, al hablar de asuntos penales, eleva su complicación por la razón que se dictará sentencia condenatoria 0 absolutoria en un plazo muy corto sin conceder el tiempo adecuado. A pesar de que la 
Corte IDH no determina con precisión un plazo en estricto sentido, recalca la importancia de hacer un análisis profundo de cada caso con la finalidad de evitar la vulneración de los derechos del debido proceso en la garantía básica de la defensa, reconocidos en la Constitución y los tratados Internacionales.

Finalmente, es indispensable señalar el análisis expuesto por Rodríguez (2011) que indica: "(...) en determinadas circunstancias, interesa más en definitiva, asegurar una sentencia justa, a través de mayores y mejores actos de defensa que tramitar el proceso con desmedida brevedad" (p.117). Esto fortalece la presente investigación respecto a la problemática planteada, en torno a que es preciso garantizar el derecho a la defensa con respeto al plazo y los mecanismos óptimos que permitan garantizar un juicio justo. En relación al procedimiento directo, éste dispone un plazo excesivamente corto para juzgar a un procesado, impidiendo una correcta práctica de diligencias en pro de esclarecer los hechos reales que originaron el caso.

\section{MÉTODO}

En el presente artículo se realizó un estudio trasversal con carácter descriptivoexplicativo, en virtud de que su finalidad fue el análisis del derecho a la defensa como parte del debido proceso en relación al plazo establecido en el procedimiento directo del COIP, en el marco del Derecho Constitucional. Las fuentes que coadyuvaron para obtener la información fueron: libros, anuarios latinoamericanos, revistas digitales jurídicas, artículos científicos, sentencias, leyes, tratados internacionales, constituciones, legislación comparada, entre otras.

La investigación tuvo un enfoque mixto con mayor interés en el método cualitativo, pues se realizó una profunda revisión bibliográfica en temas de derechos, garantías, sentencias internacionales en relación al plazo razonable y legislaciones internacionales con características análogas al procedimiento directo. Al mismo tiempo, se empleó el método cuantitativo a través de la aplicación de encuestas, y el tratamiento de datos a través de la estadística inferencial. 
El método histórico-lógico fue empleado para señalar la evolución del procedimiento directo partiendo desde el año 2014, hasta su actual reforma del año 2019, considerando que el plazo razonable mantiene a través del tiempo una misma línea jurisprudencial, para aquello se implementó un análisis cronológico; asimismo, luego de la investigación realizada, se examinaron aspectos relevantes que llevaron a la importancia de contar con un tiempo adecuado para la defensa, para lo cual se utilizó el método analítico-sintético. A más de los ya mencionados, se aplicó el método inductivo-deductivo que permitió evaluar aspectos generales como el debido proceso y el derecho a la defensa para seguir con el procedimiento directo hasta llegar a la determinación del plazo razonable que se requiere. Así también, se aplicó el método comparativo con el fin de analizar las legislaciones de países como Bolivia, Perú, Argentina y Uruguay, en referencia a las similitudes con el procedimiento directo.

El muestreo por conveniencia que se implementó en el presente artículo investigativo, se afianzó en una técnica no aleatoria y de muestreo no probabilístico, de tal forma que, la muestra estuvo integrada de 11 personas representadas por: jueces de primer nivel, secretarios de Tribunales, fiscales, secretarios de Fiscalía, un coordinador de postgrado y Abogados en libre ejercicio profesional con experiencia en materia constitucional y penal.

\section{RESULTADOS}

El análisis realizado mediante encuestas, sobre la limitación del derecho a la defensa por el plazo establecido en el procedimiento directo, es una iniciativa de investigación enfocada en el Derecho Constitucional, con el objeto de robustecer la protección de los derechos constitucionales, por medio de la creación y aplicación de nuevos aportes jurídicos.

En tal virtud, la presente investigación tuvo un carácter académico, con la participación de conocedores en el campo constitucional como: jueces de primer nivel, fiscales, secretarios de fiscales y profesionales del derecho. Por consiguiente, fue posible alcanzar 
un nivel de valoración sobre la percepción que la población encuestada mantiene referente el derecho a la defensa y el debido proceso.

En relación a la encuesta aplicada, la misma estuvo formada de 12 preguntas con respuestas de opción múltiple preestablecidas, la cual fue dirigida a 11 personas dentro del límite ecuatoriano.

El fin de la primera interrogante fue conocer el grado de información que poseen los encuestados en relación al Derecho Constitucional, por lo que, el $100 \%$ respondió que es conocedor del derecho a la defensa cuando se le preguntó sobre el tema.

Al plantear la pregunta sobre qué parámetros considera necesarios para un efectivo goce del derecho a la defensa, el $90 \%$ de los profesionales (ver figura 1), indicaron que debe contener el tiempo necesario, medios adecuados y ser oído en el momento oportuno, lo que se enmarca con lo dispuesto por la Constitución artículo 76, en tanto que el $10 \%$ señala que solo es necesario ser oído en el momento oportuno y contar con los medios adecuados. Esto indica que un alto porcentaje de los encuestados, consideran necesario que los parámetros propuestos deben ser de disponibilidad absoluta al momento del ejercicio del derecho a la defensa. 


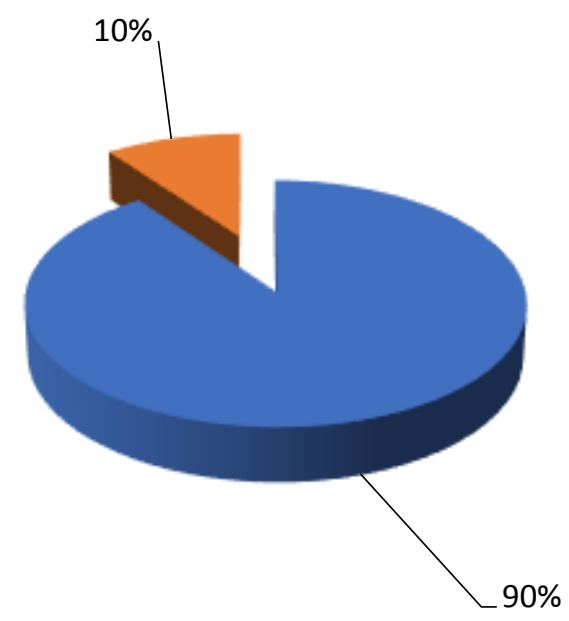

debe contener el tiempo necesario, medios adecuados y ser oído en el momento oportuno

solo es necesario ser oído en el momento oportuno y contar con los medios adecuados

Figura 1. Parámetros del derecho a la defensa

Asimismo, el $100 \%$ de la unidad de análisis considera pertinente que las personas procesadas cuenten con un plazo razonable para preparar la defensa, derecho que se encuentra consagrado en el artículo 76, numeral 7 de la Carta Magna; lo que afianza la problemática identificada en la investigación, ya que los encuestados ratifican la importancia del plazo razonable, esto vuelve indiscutible que el tiempo juega un rol muy importante a la hora de defenderse.

En virtud que la encuesta estuvo aplicada en personas conocedores del derecho, cuando se preguntó sobre el nivel de conocimiento del procedimiento directo señalado en el artículo 640 del Código Orgánico Integral Penal, el $81.80 \%$ respondieron que poseen un firme conocimiento, mientras que, el $18.20 \%$ posee un conocimiento medio, esto permitió tener la certeza que la encuesta aplicada, tiene bases sólidas para la recolección de nuevas percepciones jurídicas.

En lo concerniente a la relación que tiene el procedimiento directo y el derecho a la defensa, el $81.20 \%$ concuerda que este procedimiento se contrapone con las garantías 
básicas del debido proceso, por el escaso tiempo con el que cuentan la víctima, el procesado e incluso la Fiscalía; el $18.20 \%$ estima que no existe confrontación. Al analizar los resultados, se observa que para un alto porcentaje de los encuestados, es de suma importancia el cumplimiento de este precepto constitucional, por ser base principal para el acatamiento de los derechos frente a un litigio, el cual se encuentra viciado por la norma penal.

Al preguntar si cree que el plazo constante en el procedimiento directo es idóneo para ser juzgado, considerando que el juez llamará a la audiencia de juzgamiento en el plazo máximo de 20 días, 9 de 11 consultados que representan el $81.8 \%$, sostienen que no es un plazo idóneo, y el sobrante considera que es un plazo suficiente. De los comentarios realizados en la encuesta, manifiestan que el plazo violenta derechos fundamentales y que no es tiempo suficiente para preparar una defensa técnica ya que al hablar de plazo se contabilizan los días feriados y días de fin de semana. Como se observa, la mayoría considera que no es un plazo idóneo, es decir, la norma infra constitucional violenta los derechos constitucionales e incluso los tratados e instrumentos internacionales.

En lo concerniente a la pregunta si 20 días son suficientes para incorporar los elementos probatorios y prepara una defensa técnica, el $80 \%$ de la unidad de análisis, indica que no es suficiente el plazo otorgado en el procedimiento directo, en tanto que, el $20 \%$ sostiene que no requieren de más días para desarrollar todas sus diligencias de prueba. La interrogante tenía como objeto verificar si la población indagada requiere más tiempo o no para incorporar elementos probatorios.

Al analizar la pregunta sobre cuál sería el plazo considerado como razonable para preparar la defensa en el procedimiento directo, el 10\% de los encuestados concuerda con el actual plazo de 20 días, el $45 \%$ da la razón a 30 días, y la diferencia restante del $45 \%$ cree necesario el plazo de 45 días para preparar la defensa. Por lo que se denota, que la mayoría de los encuestados está de acuerdo que el plazo razonable figure entre 30 o 45 días. 
Respecto a establecer la necesidad de reformar el artículo 640, numeral 4 del COIP, con el fin de extender el plazo del procedimiento directo, el $90 \%$ expresa que es necesaria la reforma al plazo constante en dicho procedimiento, en virtud que es insuficiente el plazo de 20 días para ser juzgado dentro de un litigio penal.

Al preguntar a los encuestados si consideran que le es suficiente a Fiscalía el plazo previsto en el procedimiento directo para reunir sus elementos probatorios, el $82 \%$ coinciden que, aun teniendo Fiscalía el apoyo del aparataje gubernamental, le es inadecuado el plazo constante en este procedimiento, ya que puede coadyuvar a que una víctima quede sin una adecuada reparación integral o un procesado sea condenado de forma injusta.

De los datos recopilados, se deriva que el nivel de conocimiento sobre el Derecho Constitucional y el procedimiento directo dentro de los encuestados es elevado, esto conlleva a delinear la contraposición existente entre el derecho a la defensa y el procedimiento antes indicado, por no contar con el tiempo y los medios adecuados para preparar la defensa. Por lo tanto, con la presente investigación se busca viabilizar la armonía entre el plazo establecido en el procedimiento directo y la Constitución, con el fin de que se efectivicen los preceptos constitucionales y se cuente con un plazo razonable para ser juzgado. Por lo que se considera pertinente, plantear la reforma al artículo 640, numeral 7 del Código Orgánico Integral Penal, en lo concerniente a extender a cuarenta y cinco días el plazo para que se lleve a efecto la audiencia de juzgamiento.

\section{PROPUESTA}

Luego de la investigación realizada, se considera necesario presentar una propuesta Reformatoria al Código Orgánico Integral Penal, con relación a la problemática establecida, la misma busca adaptar la norma penal dentro de las disposiciones constitucionales (ver figura 3). 


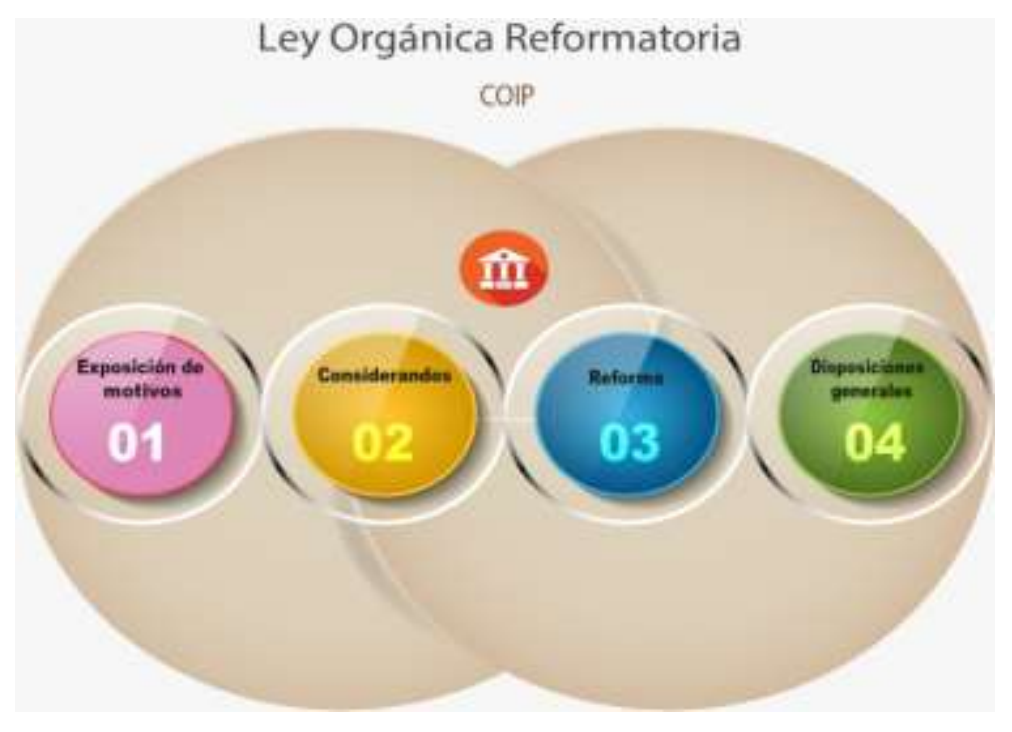

Figura 2. Reforma al Código Orgánico Integral Penal

\section{Proyecto de Ley Orgánica Reformatoria al Código Orgánico Integral Penal (COIP) Exposición de motivos}

Al ser intrínsecos los derechos fundamentales en el Derecho Constitucional ecuatoriano, es pertinente realizar un estudio del bloque normativo. En esta ocasión, se hace relevante examinar la normativa penal, puesto que su finalidad es establecer la responsabilidad penal del infractor y sancionar la conducta atentatoria a los bienes jurídicos con las penas previstas en la legislación penal; la que requiere de constantes revisiones legislativas para asegurar el cumplimiento de los preceptos constitucionales.

Según la pirámide de Kelsen utilizada para clarificar la estructura jerárquico-normativa, en la que el documento constitucional goza de supremacía sobre otras leyes, el Código Orgánico Integral Penal (COIP), es uno de los cuerpos normativos más relevantes del bloque jurídico interno, ya que diseña la convivencia pacífica de los ciudadanos, por lo que se convierte en necesario dilucidar si existe concordancia entre las disposiciones constitucionales y las actuaciones de las autoridades jurisdiccionales en el ámbito penal. 
Existe oposición entre el procedimiento directo establecido en el artículo 640, de manera específica en el numeral 4 del COIP, y el artículo 76 numeral 7 de la Constitución, letra b; en virtud de que la norma suprema otorga el derecho a las partes procesales a defenderse haciendo uso de los medios adecuados, y a ser escuchadas en el momento procesal oportuno que la ley prevé para el efecto, mientras que el procedimiento directo una vez calificada la flagrancia, fija como plazo 20 días para que se lleve a cabo la audiencia de juzgamiento.

En este contexto, la Convención Americana sobre Derechos Humanos, ratificada por el Ecuador desde el año 1977, en la parte pertinente, garantiza a las personas el derecho de contar con un plazo razonable en el momento en que requieran ser oídas. En tal razón, se manifiesta la existencia de un vacío legal en la norma penal ecuatoriana, pues se contrapone con lo dispuesto en la Constitución y los tratados internacionales, como ha quedado evidenciado.

Por los motivos antes expuestos, y en razón de que las normas jurídicas deben sujetarse a lo preceptuado en la Constitución, se exhibe la propuesta del Proyecto de Ley Orgánica Reformatoria al Código Orgánico Integral Penal.

\section{Considerando}

Que el artículo 3 de la Constitución de la República del Ecuador, dispone como uno de los deberes del Estado, garantizar el adecuado goce de los derechos constantes en la Constitución y los tratados ratificados por el Ecuador.

Que el artículo 75 de la Constitución garantiza que el acceso a la justicia sea imparcial, expedito, efectivo, conforme a los principios de celeridad e inmediación, y en ningún caso las personas quedarán en indefensión.

Que la Constitución, artículo 76, reconoce las garantías básicas del derecho a la defensa como parte del debido proceso; en el ámbito penal se asegurará a las partes procesales los derechos señalados en la carta magna. 
Que el artículo 424, inciso primero, señala que la Constitución es en jerarquía superior a las normas infraconstitucionales, las mismas que deberán estar en armonía con la Constitución. Por tanto, es obligación del aparato legislativo impulsar la modificación de la norma penal que corresponda.

Que el artículo 640 del Código Orgánico Integral Penal, es atentatorio al derecho a la defensa, señala en la Constitución, por cuanto no permite al acusado ejercer su defensa, ni cuenta con el tiempo y medios necesarios para efectuarla, ya que este procedimiento concentra el proceso de juzgamiento en una sola audiencia, en la que la autoridad judicial dicta sentencia.

Que es deber del Estado garantizar el efectivo goce de los derechos constitucionales, por lo que es necesario presentar una propuesta de reforma al Código Orgánico Integral Penal, encaminada a establecer un lapso más extenso en consonancia con un plazo razonable en lo relativo a lo que contempla el numeral 4, del artículo 640.

Por consiguiente, en uso de las atribuciones concedidas por la Constitución de la República del Ecuador, artículo 120, numeral 6, la Asamblea Nacional expide la siguiente:

\section{Ley Orgánica Reformatoria al Código Orgánico Integral Penal}

Artículo único.- Sustitúyase el numeral 4 del artículo 640, por el siguiente:

Una vez calificada la flagrancia, la o el juzgador señalará día y hora para realizar la audiencia de juicio directo en el plazo máximo de cuarenta y cinco días, dentro del cual las partes podrán solicitar a la o el fiscal la práctica de diligencias y actuaciones necesarias.

Disposiciones derogatorias.- Queda derogada toda disposición que se contraponga a la presente reforma.

Disposiciones finales.- Una vez publicada en el Registro Oficial, la presente ley entrará en vigencia en el término de ciento ochenta días. 
Dado en el Distrito Metropolitano de Quito, sede de la Asamblea Nacional de la República del Ecuador, a los diez días del mes de junio de dos mil veinte.

\section{DISCUSIÓN}

El análisis investigativo del presente artículo permite arribar a las siguientes puntualizaciones:

La Constitución de la República del Ecuador, en su artículo 76, numeral 7, letra b, otorga a las partes el derecho a la defensa, posibilitándoles contar con un tiempo adecuado y ser oídas en el momento procesal oportuno, mientras que, el artículo 640, numeral 4 del COIP, señala como plazo 20 días para que se lleve a efecto la audiencia de juzgamiento, siendo éste un plazo irracional para que las partes prepararen sus elementos probatorios y ejerzan una defensa técnica apropiada, ante esto, se evidencia la violación del derecho a la defensa presente en el procedimiento directo contemplado en la legislación penal. Asimismo, las conceptualizaciones analizadas fortalecen la presente investigación respecto a la problemática planteada, ya que se define al derecho antes mencionado como un derecho fundamental e ilimitado, por ser indispensable contar con un plazo razonable para esclarecer los hechos, puesto que, una sentencia en la que ha primado una debida práctica de diligencias, será más justa que aquella sometida a la brevedad imprudente, como es el caso del plazo señalado en el procedimiento directo.

Los resultados de la encuesta demuestran que se ha cumplido con el objetivo planteado, en vista de que, el $90 \%$ de las personas interrogadas concuerdan en la necesidad de reformar el Código Orgánico Integral Penal, en lo referente a extender el plazo dispuesto en el procedimiento directo; esta idea se refuerza con las respuestas de un $80 \%$ de encuestados que indican que no es suficiente este plazo para tramitar un litigio penal. En tal virtud, un porcentaje elevado ratifica la importancia de contar con un plazo razonable que permita un efectivo goce de los derechos constitucionales.

Del mismo modo, más del $80 \%$ de los encuestados apoyan el objeto del presente estudio, al considerar que 20 días no es un plazo idóneo para ser juzgado, es decir, esta norma 
penal violenta los derechos constitucionales e incluso los tratados internacionales ratificados por el Ecuador, de manera específica, la Convención Americana sobre Derechos Humanos que en el artículo 8.2 otorga a las personas el derecho a contar con un plazo razonable para su defensa.

Por otro lado, la propuesta anunciada también afianza la investigación, por cuanto, al ser el procedimiento directo parte de un cuerpo normativo que puede llegar a sancionar con pena privativa de libertad la conducta de los ciudadanos, se demuestra que el límite de tiempo ahí dispuesto genera una contraposición legal entre la norma penal y la Constitución. Con el fin de fortalecer la propuesta de reforma, se ha evidenciado a través del análisis de legislación comparada que procedimientos similares al procedimiento directo fijan mayores plazos para desarrollar una defensa eficaz.

A partir de lo antes detallado, queda reflejada la existencia de la vulneración del derecho a la defensa que consta en el procedimiento directo, por establecer un plazo divergente a lo establecido en la normativa constitucional y la Convención Americana sobre Derechos Humanos.

\section{FINANCIAMIENTO}

No monetario.

\section{AGRADECIMIENTO}

A la Universidad Católica de Cuenca por impulsar el desarrollo de esta investigación.

\section{REFERENCIAS CONSULTADAS}

Asamblea General de las Naciones Unidas. (10 de diciembre de 1948). Declaración Universal de Derechos Humanos. [Universal Declaration of Human Rights.]. Declaración Universal de Derechos Humanos. París, Isla de Francia, Francia: esolución 217 A (III). Obtenido de https://n9.cl/o2t5 
Asamblea Nacional Constituyente del Ecuador. (20 de octubre de 2008). Constitución de la República del Ecuador. [Constitution of the Republic of Ecuador]. Tratados e instrumentos internacionales . Quito, Pichincha, Ecuador : Registro Oficial 449. Obtenido de https://n9.cl/hd0q

Asamblea Nacional Constituyente del Ecuador. (20 de Octubre de 2008). Constitución de la República del Ecuador. [Constitution of the Republic of Ecuador]. Derechos de protección. Quito, Pichincha, Ecuador: Registro Oficial 449. Obtenido de https://n9.cl/hd0q

Asamblea Nacional del Ecuador. (10 de febrero de 2014). Código Orgánico Integral Penal. [Comprehensive Organic Penal Code]. Procedimientos especiales. Quito, Pichincha, Ecuador: Registro Oficial Suplemento 180. Obtenido de https://n9.cl/g6sc

Asamblea Nacional del Ecuador. (10 de febrero de 2014). Código Orgánico Integral Penal. [Organic Comprehensive Criminal Code.]. Plazos y horarios. Quito, Pichincha, Ecuador: Registro oficial Nro. 180. Obtenido de https://n9.cl/g6sc

Asamblea Nacional del Ecuador. (10 de febrero de 2014). Código Orgánico Integral Penal. [Organic Comprehensive Criminal Code]. Procedimientos especiales. Quito, Pichincha, Ecuador: Registro Oficial Suplemento 180. Obtenido de https://n9.cl/g6sc

Asamblea Nacional del Ecuador. (24 de diciembre de 2019). Ley Orgánica Reformatoria al Código Orgánico Procesal Penal. [Reform Law to the Organic Comprehensive Criminal Code]. Ley Orgánica Reformatoria al Código Orgánico Procesal Penal. Quito, Pichincha, Ecuador: Registro oficial 107. Obtenido de https://n9.cl/9ukf

Baculima, G., Narváez, C., Trelles, D., \& Erazo , J. (2019). Derecho a la defensa en la detención con fines investigativos. [Right to defense in detention for investigative purposes]. Iustitia Socialis. doi:http://dx.doi.org/10.35381/racji.v5i8.577

Caso Argüello y otros vs. Argentina. [Case of Argüello et al. Argentina], Nro. 12.167 (Corte Interamericana de Derechos Humanos 20 de noviembre de 2014). Obtenido de https://n9.cl/hjbb

Caso del Tribunal Constitucional vs. Perú. [Constitutional Court case vs. Peru]., Nro. (Tribunal de la Corte Interamericana de Derecho Humanos 31 de enero de 2001). Obtenido de https://n9.cl/zbw3 
Cruz-Barney, O. (2016). El código Nacional de Procedimientos Penales y la defensa a la defensa. [The National Code of Criminal Procedures and defense to defense]. Recuperado de https://n9.cl/uxc0. Instituto de Investigacioines Jurídicas-UNAM.

García, J. (26 de noviembre de 2010). El derecho al debido proceso. [The right to due process]. Obtenido de Derecho Ecuador.com: https://n9.cl/jnnqd

García, S. (2006). Panorama del debido proceso (adjetivo) penal en la jurisprudencia de la Corte Interamericana. [Overview of criminal (adjective) due process in the jurisprudence of the Inter-American Court]. Obtenido de Anuario de Derecho Constitucional Latinoamericano: https://n9.cl/ua61

Grunauer, E. (25 de enero de 2016). El cumplimiento de los parámetros del debido proceso en el procedimiento directo del Código Orgánico Integral Penal. [Compliance with the parameters of due process in the direct procedure of the Organic Comprehensive Criminal Code.]. Procedimiento Directo: Naturaleza jurídica. Quito, Pichincha, Ecuador: Repositorio Institucional UASB-DIGITAL. Obtenido de https://n9.cl/pb61e

IX Conferencia Internacional America. (1948). Declaración Americana de los Derechos Humanos y Deberes del Hombre. [American Declaration of the Rights and Duties of Man]. Deberes. Bogotá, Cundinamarca, Colombia. Obtenido de https://n9.cl/9uxk

Ministerio de Justicia. (18 de mayo de 2010). Código del Procedimeito Penal, Ley Nro. 007. [Code of Criminal Procedure, Law No. 007] . Procedimiento inmediatos para delitos flagrantes. La Paz, La Paz, Bolivia: Gaceta Oficial del Estado Plurinacional de Bolívia. Obtenido de https://n9.cl/9lh6

Organización de Estados Americanos. (22 de noviembre de 1969). Convención Americana sobre Derechos Humanos. [American Convention on HUman Rights]. Derechos civiles y políticos. San José, San José, Costa Rica: Gaceta Oficial Nro. 9460. Obtenido de https://n9.cl/780p

Pacto Internacional de Derechos Civiles y Políticos. (16 de diciembre de 1966). Pacto Internacional de Derechos Civiles y Políticos. [International Covenant on Civil and Political Rights]. Recuperado de: https://n9.cl/ijeh. 
Rivadeneyra, A. (2010). El derecho al plazo razonable como contenido implicito al derecho a la defensa: Desarrollo jurisprudencial a nivel inteacional y nacional. [The right to a reasonable time as implicit content of the right to defense: Jurisprudential development at the in]. Revista Internauta de Práctica Jurídica, 43-59. Obtenido de https://n9.cl/1qsy7

Rodríguez , C. (2011). El plazo razonable en el marco de las garantías judiciales en colombia. [The reasonable period of time within the framework of judicial guarantees in Colombia]. Recuperado de: https://n9.cl/50dd. Memorando de Derecho, 117.

Rojas, M., Erazo, J., Pozo, E., \& Narváez, C. (2019). Prueba en Garantías Jurisdiccionales. Falta de regulación y afección al derecho a la defensa y libertad probatoria en el Ecuador [Proof of Jurisdictional Guarantees. Lack of regulation and impact on the right to defense and probation in Ecuador]. Iustitia Socialis, 30. doi:http://dx.doi.org/10.35381/racji.v5i8.560

Santos, J. (2009). El debido proceso penal. [Due process of law]. Quito, Ecuador: Corporaciones de estudios y publicaciones Quito.

Senado y Cámara de Diputados de la Provincai de Buenos Aires. (7 de abril de 2008). Ley 13811. Procedimieto en la Etapa de Juicio. [Procedure in the Trial Stage.]. La Plata, Buenos Aires, Argentina: Boletín oficial Nro. 25873. Obtenido de https://n9.cl/flg6d

Senado y Cámara de Representantes de la República Oriental del Uruguay. (9 de enero de 2015). Código del Proceso Penal. [Code of Criminal Procedure]. De la acusacion y la defensa. Montevideo, Montevideo, Uruguay: Registro Nacional de Leyes y Decretos. Obtenido de https://n9.cl/8n99x

Tarazona Arrieta y otros vs. Perú. [Tarazona Arrieta and others vs. Peru], Nro. 11.581 (Tribunal de la Corte Interamericana de derechos Humanos 15 de octubre de 2014). Obtenido de https://n9.cl/x34z 